\title{
On the Nature of Root and Adjunct Clauses
}

\author{
Miki Obata* \\ LSA Annual Meeting, Minneapolis, January 2-5, 2014
}

1. The Matrix/Complement Asymmetry. The goals of this paper are to re-examine some cases of scope interaction between the Japanese universal quantifier zen'in (= 'all') and negation nai (= 'not') discussed in Miyagawa (2001, 2003, 2010), and also to clarify some important theoretical implications especially for mechanisms of the Transfer operation.

In English, the universal quantifier everyone in the subject position can take both wide scope and narrow scope to negation as in (1). In Japanese, on the other hand, the universal quantifier zen'in in the subject position cannot take narrow scope to negation but take only wide scope to negation as in (2).

(1) English

Everyone had not left the party.

(2) Japanese

[Scope: $\checkmark$ not $>$ every, $\checkmark$ every $>$ not]

Zen'in-ga siken-o uke-nakat-ta.

all-Nom test-Acc take-Neg-Past

'All did not take the test.'

[Scope: *not>all, $\sqrt{ }$ all $>$ not $]$

(Miyagawa 2010)

Miyagawa (2010) explains this parametric variation by appeal to what triggers movement of the subject from Spec-vP to Spec-TP. He argues that languages can be classified into agreement languages (e.g. English) and discourse-configurational languages (e.g. Japanese). The only difference between them is what triggers movement at $\mathrm{T}$ : phi-probe in agreement languages and topic/focus in discourse-configurational languages.

Let us see how the system works for the cases in (1) and (2). In English (1), T phi-agrees with the subject and the phi-probe T attracts everyone to Spec-TP. In Japanese (2), on the other hand, topic/focus features inherited from C to T attracts zen'in to Spec-TP. He suggests that this movement can be regarded as a type of topicalization. As discussed in Kiss (1995), the topic in a topic-prominent language (e.g. Japanese) is, in a way, an alternative to the subject. That is, everyone and zen'in are moved by different triggers under this approach: phi-probe vs.

topic/focus. Furthermore, Miyagawa suggests that different triggers of movement generate different scope interactions: A-movement triggered by phi-probe can leave copies, causing 'every>not' and 'not>every' in (1). Meanwhile, A-movement triggered by topic/focus leaves no copy, so that 'not>all' is unavailable in (2).

Interestingly, Saito (2006) points out that the other reading 'not>all' is available by embedding (2) into another clause as illustrated in (3) and that lack of 'not>all' observed in (2) is, in fact, limited in root clauses (i.e. the matrix/complement asymmetry).

(3) Zen'in-ga siken-o eraba-na-i to omou.

all-Nom test-Acc choose-Neg-Pres $\mathrm{C}$ think

'I think that all will not choose an exam (over a term paper).'

[Scope: $\sqrt{ }$ not $>$ all, $\sqrt{ }$ all $>$ not $]$

(Saito 2006)

*Author: Miki Obata, Tokyo University of Science (obata@rs.tus.ac.jp) 
Miyagawa (2010) explains the 'not>all' reading in (3) by saying that topic is 'less apt to appear' in the embedded clause. Since there is no feature triggering movement (i.e. topic) on complement $\mathrm{T}$ in (3), the subject zen'in stays at Spec-vP (i.e. inside of negation). Although Miyagawa does not clearly account for the other reading 'all>not', a topic feature 'can' appear on complement $\mathrm{T}$ (since he does not deny the possibility) and the subject zen'in is moved to Spec-TP (i.e. outside of negation).

2. Selected CP vs. Unselected CP. Interestingly, the 'not $>$ all' reading disappears again by putting (2) in adjunct clauses. The root effect (2) is observed in the adjunct clause (4)-(7), but not in the complement clause (3).

\section{Adjunct Clauses: Reason}

(4) Zen'in-ga siken-o uke-nakat-ta kara, saiten-suru hituyo-ga nai. all-Nom test-Acc take-Neg-Past because grade-do need-Nom Neg

'Because all did not take the test, I do not need to grade it.'

(5) ??Zen'in-ga siken-o uke-nakat-ta kara, saiten-suru hituyo-ga aru. all-Nom test-Acc take-Neg-Past because grade-do need-Nom exist 'Because all did not take the test, I need to grade it.'

Adjunct Clauses: If-clause ${ }^{1}$

(6) Zen'in-ga siken-o uke-nakat-ta-ra, saiten-suru hituyo-ga nai. all-Nom test-Acc take-Neg-Past-if grade-do need-Nom Neg 'If all do not take the test, I do not need to grade it.'

(7) ??Zen'in-ga siken-o uke-nakat-ta-ra, saiten-suru hituyo-ga aru. all-Nom test-Acc take-Neg-Past-if grade-do need-Nom exist 'If all do not take the test, I need to grade it.'

In (4)-(5), only 'all>not' is available. If there is at least one person who took the test (i.e. if 'not>all' is available), (5) should be equally acceptable since at least one answer sheet to be graded exists. The same discussion is applicable to (6)-(7). These data tell us that the 'not>all' reading is unavailable in adjunct clauses as well as in root clauses. That is, the asymmetry is observed not between matrix clauses and complement clauses but between selected CP (i.e. complement CP) and unselected CP (i.e. root and adjunct CP). Extending Miyagawa's (2010) analysis, $\mathrm{C} / \mathrm{T}$ in adjunct clauses behave in the same way as $\mathrm{C} / \mathrm{T}$ in root clauses in that topic features always trigger movement of the subject to Spec-TP in contrast to $\mathrm{C} / \mathrm{T}$ in complement clauses.

3. Theoretical Implications. The findings presented in Section 2 imply that root and adjunct CPs, but not complement CPs, share certain properties. In fact, this dichotomy is supported also by mechanisms of the Transfer operation.

Under the phase-based derivational approach (Chomsky 2004), syntactic representations generated in narrow syntax are sent to the interfaces phase by phase, so that computational complexity can be reduced by 'forgetting' already completed representations. Although Chomsky (2004) argues that Transfer is applied to the complement of a phase head, it is obvious that there

\footnotetext{
${ }^{1}$ Saito (2006) also presents if-clause cases and argues that both readings are available. The data presented in (4)-(7) are based on my informants' judgment and my own judgment. The contexts in (6)-(7) appear to ameliorate their acceptability.
} 
are some cases that the entire phase, not just the complement, needs to be sent to the interfaces. Obata (2010) suggests that Transfer sends as many representations as possible (unless it causes the derivation to crash). For example, embedded $\mathrm{C}$ needs to construct a selectional dependency with a higher $\mathrm{V}$, so that embedded $\mathrm{C}$ needs to remain in narrow syntax until the next higher phase $\mathrm{vP}$ is introduced. (Also, Case on the external argument at the edge of $\mathrm{vP}$ is not valued until $\mathrm{T}$ included in the next phase gets into the derivation, so that the edge of $\mathrm{vP}$ needs to be left when its complement is transferred.)

On the other hand, Transfer needs to be applied to the entire phase in the case of root and adjunct $\mathrm{CP}$, which are both unselected $\mathrm{CP}$. Apparently, root $\mathrm{CP}$ has no chance to be included in the complement of any phase head. Also, since no element can be extracted out of adjunct CP because of adjunct islands, the edge of adjunct CP cannot be left after transferring its complement. (See Uriagereka 1999 for more detail.) That is, Transfer is limited to the complement of $\mathrm{C}$ in the case of embedded $\mathrm{CP}$ while the entire $\mathrm{CP}$ has to be transferred in the case of root and adjunct CP. The same dichotomy as the scope interaction cases in Japanese is observed also in the Transfer operation.

4. Summary and Remaining Issues. In this paper, I demonstrated that scope interaction between zen'in (='all') and negation in Japanese shows asymmetries between selected CP and unselected $\mathrm{CP}$, but not between matrix CP and complement CP. Also, the same asymmetry is obtained in the Transfer operation. The observation observable here implies possibilities that the distinction between selected CP and unselected CP plays some important roles in human linguistic computation.

One of the remaining issues is to clarify how the scope interaction cases and the Transfer operation can be related. Although they both obey the same dichotomy, they are still independent phenomena. Further research is required to elucidate some mechanisms behind these two cases.

\section{References}

Chomsky, Noam. 2004. Beyond explanatory adequacy. In Structures and beyond, ed. Adriana Belletti, 104-131. Oxford: Oxford University Press.

É. Kiss, Katalin. 1995. Introduction. In Katalin É. Kiss. ed., Discourse configurational languages, 3-27. Oxford: Oxford University Press.

Miyagawa, Shigeru. 2001. The EPP, scrambling, and wh-in-situ. In M. Kenstowicz. ed. Ken Hale: A Life in Language, 293-388. Cambridge, Mass.: MIT Press.

Miyagawa, Shigeru. 2003. A-movement scrambling and options without optionality. In S. Karimi. ed. Word Order and Scrambling. Blackwell Publishers.

Miyagawa, Shigeru. 2010. Why Agree? Why Move? Unifying Agreement-Based and Discourse-Configurational

Languages, Cambridge, MA: MIT Press.

Obata, Miki. 2010. Root, Successive-Cyclic and Feature-Splitting Internal Merge: Implications for Feature-Inheritance and Transfer. Ph.D. thesis, University of Michigan, Ann Arbor.

Saito, Mamoru. 2006. Optional A-scrambling. Paper presented at the sixteenth Japanese/Korean Linguistics Conference.

Uriagereka, Juan. 1999. Multiple spell-out. In Working minimalism, eds. Samuel David Epstein and Norbert Hornstein, 251-282. Cambridge, MA: MIT Press. 